\title{
The Challenge of the Unacceptable High Mortality in End-Stage Kidney Disease: Is Folic Acid the Answer?
}

\author{
Dierik L. Verbeelen \\ Renal Unit, Academisch Ziekenhuis VUB, Brussels, Belgium
}

In an article published in this issue of Blood Purification, Righetti et al. give evidence for a beneficial effect of low-dose folic acid treatment on cardiovascular morbidity compared to no supplement [1]. Two previous studies in hemodialysis patients have not shown a beneficial effect in groups comparing multivitamins and 1, 5 and 15 $\mathrm{mg}$ folic acid [2] or three different high-dose regimes of folic acid: 15, 30 and $60 \mathrm{mg}$ [3]. Also in patients with chronic kidney disease, studied in the AFSAT trial (15 mg folic acid compared to placebo), no slowing of atheroma progression or a change in cardiovascular mortality and morbidity could be found [4]. In the general population the effect of homocysteine lowering by folic acid does not result in a lowering of the combined end point of vascular events and mortality, although there seems to be a trend towards less stroke incidence [5]. So there are different studies in different populations with different dose regimens and different results. What conclusions can be drawn from these interventions?

In all studies a significant lowering of total homocysteine has been observed. Although folic acid reduces the risk factor 'high plasma homocysteine', it is only part of the story. As discussed by the authors and also summarized by Suliman et al. [6], there is the paradoxical relationship in end-stage renal disease between high homocysteine and better survival. This may be explained by the fact that both malnutrition and diabetes lower homocys-

\section{KARGER}

Fax +41613061234 E-Mail karger@karger.ch www.karger.com
(C) 2006 S. Karger AG, Basel

0253-5068/06/0244-0377\$23.50/0

Accessible online at:

www.karger.com/bpu teine. So it may be that in some particular patient population a reduction in homocysteine may help and in others it may not. It may be that not lowering homocysteine but normalizing folic acid levels may explain the beneficial effect observed in some studies.

Is it necessary to repeat interventional trials that have proved unsuccessful in a general patient population? It has previously been claimed that findings in other populations can be transposed to patients with end-stage renal disease. Is this the case? Non-modifiable risk factors, e.g. age, previous cardiovascular problems and diabetes, are related to morbidity and mortality in the same way as in a general population. Amongst the modifiable risk factors, the relationship is less clear. Body weight, serum cholesterol, homocysteine and blood pressure are not or are even inversely correlated $[7,8]$. These observations indicate that the impact of risk factors in the dialysis population is different and that observations in general cannot be transposed to dialysis patients. A lot of observational information has been collected. However we should only rely on prospective information to guide treatment.

What is the evidence from the few prospective randomized interventional trials that have been conducted in dialysis patients? Fosinopril has been studied in dialysis patients with left ventricular hypertrophy and, although the results have not been formally published, preliminary presentation revealed no significant effect on a combined 
end point of mortality and cardiovascular morbidity [9, 10]. Similarly atorvastatin $20 \mathrm{mg}$ did not show a beneficial effect on cardiovascular death and morbidity in type- 2 diabetes patients on hemodialysis for a period of less than 2 years [11].

In dialysis patients with dilated cardiomyopathy, administration of carvedilol showed a reduction in cardiac deaths and hospitalization rate. In this relatively small study the reduction rate for all-cause mortality was 0.51 and for cardiovascular death 0.31 [12]. Patients with kidney disease, especially on renal replacement therapy, have increased oxidative stress. Two studies have shown that administration of acetylcysteine or vitamin E supplements decreases the risk of reaching a combined end point (death and cardiovascular event) $[13,14]$. This is at variance with large studies in the general population showing that antioxidant treatment does not influence outcome. The three trials with folic acid and vitamin supplements show contradictory results. The reason for the discrepancy between the general and dialysis population remains obscure, but the point is that dialysis patients need to be considered as a particular and specific group. Moreover the dialysis population is heterogeneous: hypertension, diabetes, kidney disease, gender and many other characteristics or co-morbidities may influence mortality and the effect of treatment. This is also illustrated in this study since nutrition influences outcome, especially in the treated group with low homocysteine.

Because mortality ranges between 15 and 30\%/year, the 1-year post-myocardial infarction mortality is $59 \%$, and because of the above-mentioned discrepancies between epidemiology and cardiovascular risk factors and the different results of controlled trials, there is an urgent need for new prospective trials to study the effects of both old and new drugs. These studies should be carefully designed, taking into account all available information in order to select patients correctly and to maximize the results of our work. The ultimate goal should be the reduction of mortality and morbidity in the dialysis population.

Nephrologists need to stimulate governments, scientific organizations, industry and everyone involved to overcome this unacceptable handicap of our patients.

\section{References}

1 Righetti M, Serbelloni P, Milani S, Ferrario GM: Homocysteine-lowering vitamin B treatment decreases cardiovascular events in hemodialysis patients. Blood Purif 2006;24:379386.

2 Wrone EM, Hornberger JM, Zehnder JL, McCann LM, Coplon NS, Fortmann SP: Randomized trial of folic acid for prevention of cardiovascular events in end-stage renal disease. J Am Soc Nephrol 2004;15:420-426.

3 Sunder-Plassmann G, Födinger M, Buchmayer H, Papagiannopoulos M, Wojcik J, Kletzmayr J, Enzenberger B, Janata O, Winkelmayer WC, Paul G, Auinger M, Barnas U, Hörl WH: Effect of high dose folic acid therapy on hyperhomocysteinemia in hemodialysis patients: results of the Vienne Multicenter Study. J Am Soc Nephrol 2000;11:11061116.

4 Zoungas S, , McGrath BP, Branley P, Kerr PG, Muske C, Wolfe R, Atkins RC, Nicholls K, Fraenkel M, Hutchison BG, Walker R, McNeil JJ: Cardiovascular morbidity and mortality in the Atherosclerosis and Folic Acid Supplementation Trial (ASFAST) in chronic renal failure: a multicenter, randomized, controlled trial. J Am Coll Cardiol 2006;47:1108-1116.
5 Loscalzo J: Homocysteine trials - clear outcomes for complex reasons. N Engl J Med 2006;354:1629-1632.

6 Suliman ME, Bárány P, Kalantar-Zadeh K, Lindholm B, Stenvinkel P: Homocysteine in uraemia - a puzzling and conflicting story. Nephrol Dial Transplant 2005;20:16-21.

7 Nurmohamed SA, Nubé MJ: Reverse epidemiology: paradoxical observations in haemodialysis patients. Neth J Med 2005;63:376381.

8 Kalantar-Zadeh K, Block G, Horwich T, Fonarow GC: Reverse epidemiology of conventional cardiovascular risk factors in patients with chronic heart failure. J Am Coll Cardiol 2004;43:1439-1444.

9 Zannad F, Kessler M, Grünfeld JP, Thuilliez C, the FOSIDIAL Investigators: FOSIDIAL: a randomised placebo controlled trial of the effects of fosinopril on cardiovascular morbidity and mortality in haemodialysis patients. Study design and patients' baseline characteristics. Fundam Clin Pharmacol 2002;16:353360.

10 Coletta AP, Cleland JG, Freemantle N, Clark AL: Clinical trails update from the European Society of Cardiology Heart Failure meeting: SHAPE, BRING-UP 2 VAS, COLA II, FOSIDIAL, BETACAR, CASINO and meta-analysis of cardiac resynchronisation therapy. Eur J Heart Fail 2004;6:673-676.
11 Wanner C, Krane V, März W, Olschewski M, Mann JFE, Ruf G, Ritz E: Atorvastatin in patients with type 2 diabetes mellitus undergoing hemodialysis. N Engl J Med 2005;353: 238-248.

12 Cice G, Ferrara L, D’Andrea A, D’Isa S, Di Benedetto A, Cittadini A, Russo PE, Golino P, Calabrò R: Carvedilol increases two-year survival in dialysis patients with dilated cardiomyopathy. A prospective, placebo-controlled trial. J Am Coll Cardiol 2003;41:1438-1444.

13 Boaz M, Smetana S, Weinstein T, Matas Z, Gafter U, Iaina A, Knecht A, Wiessgarten Y, Brunner D, Fainaru M, Green MS: Secondary prevention with antioxidants of cardiovascular disease in endstage renal disease (SPACE): randomised placebo-controlled trial. Lancet 2000;356:1213-1218.

14 Tepel M, van der Giet M, Statz M, Jankowski J, Zidek W: The antioxidant acetylcysteine reduces cardiovascular events in patients with end-stage renal failure. Circulation 2003;107: 992-995. 